\title{
Enteral stenting in 21 patients with malignant gastroduodenal obstruction
}

\author{
Tjun Tang MB BChir Mike Allison MD MRCP ${ }^{1}$ Irene Dunkley BSc RN ${ }^{2}$ \\ Phil Roberts MD MRCP2 Richard Dickinson MD FRCP
}

J R Soc Med 2003;96:494-496

\section{SUMMARY}

Placement of an enteral stent is emerging as an effective alternative to surgery for symptomatic relief in patients with malignant gastric outflow and duodenal obstruction. We report experience in a series of patients who had the Wallstent enteral prosthesis inserted.

21 consecutive patients with inoperable obstruction, median age 75 years, had twenty-three procedures for insertion of the Wallstent under fluoroscopic guidance. Stent implantation was successful in 18 patients (86\%), all of whom gained relief from nausea and vomiting. There were no short-term complications. Median survival after the procedure was four months (longest ten months), and no deaths were related to insertion.

The efficacy and lack of complications in this series support use of the endoscopically placed stent for palliative management of malignant upper gastrointestinal obstruction.

\section{INTRODUCTION}

In a patient with malignant gastroduodenal obstruction, the last few months of life are often dominated by nausea and vomiting, leading on to starvation. Surgical palliation is possible with construction of a bypassing gastrojejunostomy but the morbidity and mortality of surgery are high in these debilitated patients; furthermore, only half gain adequate symptomatic relief. ${ }^{1,2}$ An alternative to surgery in these circumstances is now offered by enteral stents inserted under endoscopic and fluoroscopic guidance. This technique has a good safety record but little has been reported on long-term clinical outcomes. We report here our 3-year experience with endoscopic insertion of the Wallstent to relieve malignant gastrointestinal outflow obstruction.

\section{METHODS}

21 consecutive patients with malignant upper gastrointestinal strictures were prospectively studied. Their disease was beyond surgical cure and all had nausea and

Vascular Unit and 'Transplant Unit, Addenbrooke's NHS Trust, Cambridge; Department of Medicine, Hinchingbrooke NHS Trust, UK

Correspondence to: Dr R J Dickinson, Consultant gastroenterologist, Department of Medicine, Hinchingbrooke Hospital, Hinchingbrooke Park, Huntingdon PE29 6NT, UK vomiting. They were admitted as inpatients for implantation of the Wallstent (Boston Scientific Microvasive), which was inserted under fluoroscopic and endoscopic guidance as previously described. ${ }^{3}$ Technical success was defined as satisfactory stent deployment and re-establishment of luminal patency. Clinical outcome was recorded in terms of relief of intestinal obstruction and palliation of symptoms.

\section{RESULTS}

Twenty-three procedures were attempted in 21 patients, whose details are summarized in Table 1 . Their median age was 75 years (range 40-88). In two-thirds of cases the primary cancer was pancreatic.

Stent implantation was technically successful in 18 (85\%) patients. On two occasions a guidewire could not be passed because of the duodenal obstruction and, in a third, a previously placed plastic biliary stent could not be reached for removal, thus preventing enteral stent placement. These 3 patients went on to have a laparoscopic gastrojejunostomy. In all the patients who had successful stent placement, nausea and vomiting improved and caloric intake returned to maintenance levels. There were no short-term complications. Stent migration was seen in only one case, during initial placement. 2 patients who were successfully stented 


\begin{tabular}{|c|c|c|c|c|c|c|c|c|}
\hline Patient & Age & Sex & Tumour & Stenosis & Stent(s) & Complications & Pain & Time to death \\
\hline 1 & 40 & $\mathrm{~F}$ & Metastatic & D1/D2 & 1 & None & None & 2 weeks \\
\hline 2 & 79 & $\mathrm{~F}$ & Pancreatic & D2/D3 & 1 & None & None & 2 months \\
\hline 3 & 52 & $\mathrm{~F}$ & Gastric & Pyloric & 2 & Early vomiting & None & 10 months \\
\hline 4 & 86 & $\mathrm{~F}$ & Pancreatic & D1/D2 & 1 & None & None & 6 months \\
\hline 5 & 71 & $\mathrm{~F}$ & Pancreatic & $\mathrm{D} 1 / \mathrm{D} 2$ & 0 & Technical failure & - & - \\
\hline 6 & 68 & $\mathrm{~F}$ & Pancreatic & D1/D2 & 1 & None & None & 3 months \\
\hline 7 & 75 & $\mathrm{~F}$ & Pancreatic & D1/D2 & 1 & None & Little & 3 months \\
\hline 8 & 83 & $\mathrm{~F}$ & Pancreatic & D1/D2 & 1 & None & None & 1 month \\
\hline 9 & 82 & $\mathrm{~F}$ & Gastric & Antral & 2 & 2nd stent & Little & 10 months \\
\hline 10 & 79 & M & Gastric & Pyloric & 2 & 2nd stent & None & 6 months \\
\hline 11 & 75 & M & Pancreatic & D1/D2 & 1 & None & None & Lost \\
\hline 12 & 78 & M & Gastric & Pyloric & 1 & None & None & 7 months \\
\hline 13 & 83 & M & Pancreatic & D1/D2 & 1 & None & None & 2 months \\
\hline 14 & 66 & M & Pancreatic & D1/D2 & 2 & Vomiting 3 weeks & None & 4 months \\
\hline 15 & 77 & M & Pancreatic & D1/D2 & 1 & None & Little & 2 months \\
\hline 16 & 70 & M & Gastric & Pyloric & 1 & None & None & 3 months \\
\hline 17 & 61 & M & Pancreatic & D1/D2 & 2 & 2nd stent & Little & 6 weeks \\
\hline 18 & 65 & M & Pancreatic & D1/D2 & 1 & None & None & 9 months \\
\hline 19 & 54 & M & Pancreatic & D1/D2 & 0 & Technical failure & - & - \\
\hline 20 & 88 & M & Gastric & Anastomosis & 1 & None & None & 1 month \\
\hline 21 & 72 & M & Pancreatic & D1/D2 & 0 & Technical failure & - & - \\
\hline
\end{tabular}

D1/D2=1st and 2nd parts of duodenum

reported abdominal pain after the procedure but this responded to simple analgesia. 2 patients were readmitted with severe vomiting at six and nine months, respectively. In one, tumour had overgrown the edge of the prosthesis; in the other, distortion of the stent itself was causing mechanical obstruction (Figure 1). In both cases further coaxial stents were inserted to bridge the stenosis. 17 patients (94\%) died during the follow-up period, all from causes unrelated to the stent insertion. Median survival was four months, longest ten months. One patient was lost to follow-up.

\section{DISCUSSION}

Our experience with this series, conducted in a district general hospital, supports the findings from major centres $^{4-6}$ that more than $70 \%$ of patients with malignant upper gastrointestinal strictures not amenable to surgery obtain relief from an endoscopically placed enteral stent. The dearth of information on long-term outcomes reflects the short life expectancy of these patients; mean survival is about thirteen weeks. ${ }^{5,7,8}$ The reported complications include ulceration caused by the stent wires, ${ }^{9}$ bleeding, stent migration, mechanical occlusion, and perforation. . 10,11 Technical difficulties are few. In some instances unfavourable angulation between the oesophagus and gastric antrum, or complete stenosis, makes the guidewire hard to pass. In our early experience there was a tendency to pass the stent distally, which with the forward force generated by opening of the stent led to less than ideal placing. Stent migration was seen in only one case, soon after insertion, and tumour overgrowth in another; we cannot comment on whether these will be commonly encountered in the long term. Perhaps the most troublesome complication is that, over time, the stent can shorten and straighten, leading to duodenal abutment and obstruction (Figure 1). In one patient in our care, whose stent was inserted elsewhere, this led to perforation. Further coaxial stents are readily deployed to bypass the obstruction. 

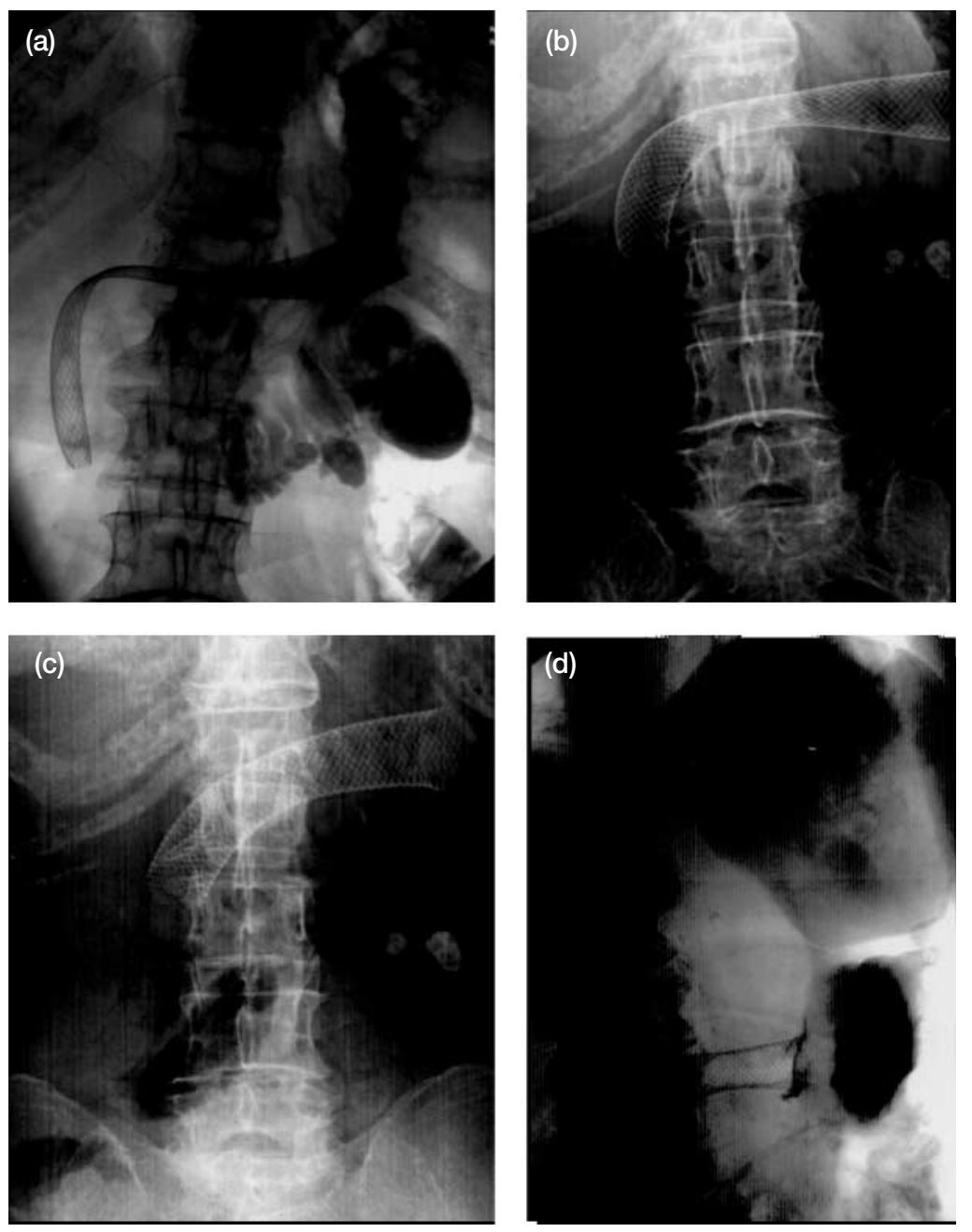

Figure 1 Shortening and straightening of stent, leading to duodenal obstruction

\section{REFERENCES}

1 Monson JR, Donohue JH, Mcllrath DC, Farnell MB, Ilstrup DM. Total gastrectomy for advanced cancer: a worthwhile palliative procedure. Cancer 1991;68:1863-8

2 Kikuchi S, Tsutsumi O, Kobayashi N, et al. Does gastrojejunostomy for unresectable cancer of the gastric antrum offer satisfactory palliation? Hepatogastroenterology 1999;46:584-7

3 Soetikno RM, Carr-Locke DL. Expandable metal stents for gastricoutlet, duodenal and small intestinal obstruction. Gastrointest Endosc Clin N Am 1999;9:447-58

4 Yim HB, Jacobson BC, Saltzman JR, et al. Clinical outcome of the use of enteral stents for palliation of patients with malignant upper GI obstruction. Gastrointest Endosc 2001;53:329-32

5 Soetikno RM, Lichtenstein DR, Vandervoort J, et al. Palliation of malignant gastric outlet obstruction using an endoscopically placed Wallstent. Gastrointest Endosc 1998;47:267-70
6 Pinto IT. Malignant gastric and duodenal stenosis: palliation by peroral implantation of a self-expanding metallic stent. Cardiovasc Intervent Radiol 1997;20:431-4

7 Yates MR, Morgan DE, Baron TH. Palliation of malignant gastric and small intestinal strictures with self-expandable metal stents. Endoscopy 1998;30:266-72

8 Bethge N, Breitkreutz C, Vakil N. Metal stents for the palliation of inoperable upper gastrointestinal stenoses. Am $J$ Gastroenterol 1998;93:643-5

9 Feretis C, Benakis P, Dimopoulos C, et al. Palliation of malignant gastric outlet obstruction with self-expanding metal stents. Endoscopy 1996;28:225-8

10 De Baere T, Harry G, Ducreux M, et al. Self-expanding metallic stents as palliative treatment of malignant gastroduodenal stenosis. Am J Roentgenol 1997;169:1079-83

11 Canon CL, Baron TH, Morgan DE, Dean PA, Koehler RE. Treatment of colonic obstruction with expandable metal stents: radiological features. Am J Roentgenol 1997;168:199-205 